\title{
Agências da imagem. \\ Uma entrevista com o Professor Wenceslao Machado de Oliveira Junior
}

O Professor Wenceslao Machado de Oliveira Junior, graduado em Geografia e Doutor em Educação, é professor no Departamento de Educação, Conhecimento, Linguagem e Arte e pesquisador do Laboratório de Estudos Audiovisuais - OLHO, ambos da Faculdade de Educação da Universidade Estadual de Campinas - UNICAMP/SP. Pesquisa na interface entre imagens e educação em suas conexões com as geografias que dela se desdobram, se descobrem, se criam, se extraem... Atualmente tem focado mais nas relações e experimentações entre cinema e escola. Tem artigos publicados onde vídeos, filmes, fotografias e mapas se misturam a conceitos e autores em escritos que visam aproximações da educação visual contemporânea $\mathrm{e}(\mathrm{m})$ suas políticas e poéticas que afetam $\mathrm{o}$ pensamento espacial. Coordenou a Rede Internacional "Imagens, Geografias e Educação" entre 2010 e 2015 e realizou o Pós-doutorado "As geografias menores em obras em vídeo de três artistas contemporâneos" na Universidade do Minho/Portugal.

\author{
Entrevistador \\ Marcelo Róbson Téo \\ Doutor em História Social pela \\ Universidade de São Paulo - USP. \\ Brasil \\ marceloteo@hotmail.com
}

Entrevista concedida em: 08/05/2016

\section{Para citar esta entrevista:}

OLIVEIRA JUNIOR, Wenceslao Machado de. Agências da imagem. Uma entrevista com o Professor Wenceslao Machado de Oliveira Junior. [Entrevista concedida em 08 de maio de 2016]. Revista PerCursos. Florianópolis, v. 17, n.33, p. 162 - 175, jan./abr. 2016. Entrevistador: Marcelo Róbson Téo.

\section{DOI: $10.5965 / 1984724617332016162$}

tttp://dx.doi.org/10.5965/1984724617332016162 
PerCursos: As imagens têm marcado presença cada vez mais intensa no campo da educação, mas ainda são raras as produções voltadas à alfabetização (no sentido freireano) visual, que requer não apenas o desenvolvimento de habilidades de leitura crítica mas, sobretudo, a prática (técnica e criação) na construção de narrativas (áudio)visuais. Como a academia pode contribuir, em termos de pesquisa, para alcançar esta conquista no espaço escolar?

Wenceslao Machado: A mais importante contribuição que a academia pode dar seria pesquisar junto e com as escolas, tomando cada espaço escolar como um lugar onde se produzem imagens porque é um lugar de experiências singulares e intensas, passíveis de gestar imagens que fazem pensar; fazem pensar, inclusive, as próprias imagens. Como a pergunta indica, o sentido freireano para a educação me parece ser de que o aprendizado é atravessado pela experiência e que, portanto, valorizar a experiência singular é favorecer aprendizados através daquilo mesmo que mobiliza alguma experiência a se desdobrar em outras experiências. Assim tenho pensado a relação entre escola e cinema, por exemplo, a partir de dispositivos de produção de imagens diversas em ambientes escolares, tomando esses ambientes escolares como algo que extrapola o prédio da escola e se espraia para tudo aquilo que atravessa a escola, a afeta e é afetado por ela. Pode incluir o bairro todo ou o mundo, as comunidades religiosas e a administração pública da cidade, as tradições de brincadeiras entre irmãos, as técnicas de pintura de algum pai ou mãe pintores de parede ou de telas, as roupas usadas pelos professores e professoras... enfim, a escola como campo de experiências mais vastas que atravessam os corpos humanos que por ali circulam e que poderiam transpassar as disciplinas escolares com um pouco mais de vida indisciplinada, que é a vida comum, cotidiana.

Particularmente desconfio das ideias de alfabetização e leitura crítica. Ambas remetem para coisas que "temos que saber" e por isso, via de regra, são definidas por especialistas que dizem o quê e como os professores devem fazer para levar os estudantes a tornarem-se alfabetizados e a fazerem leituras críticas. Se para a língua escrita isso já é contestado faz um bom tempo, dobrar essas ideias sobre as imagens me parece um contrassenso porque, ao contrário da língua escrita, o entendimento/aprendizado das imagens é realizado na própria convivência social com elas bem antes da escolarização, dispensando um processo formal de alfabetização. Além disso, penso estarmos todos aptos a produzir, ver e ler imagens, cabendo muito mais colocar essas produções, visões 
e leituras em diálogo do que propriamente alfabetizar ou promover atividades de leitura crítica delas. Isso porque a crítica, em sentido amplo, irá se estabelecer através desses diálogos de maneira mais diversificada e localizada nos problemas que emanarem daquelas imagens e daquelas visões e leituras postas em diálogo. Não tenho nenhuma dúvida de que as visões e leituras de um professor que tenha se formado com o gosto pela pesquisa terá um papel muito instigador nesses grupos de conversa com as imagens, pois ele muito provavelmente irá pautar mais e mais perguntas para as imagens, pois sabe que o conhecimento e o pensamento são mais abrangentes e encarnados se e quando não se esgotam as perguntas feitas a eles. Gosto especialmente da perspectiva de aprendizado traçada no livro "O mestre ignorante"e da ideia de emancipação proposta no ensaio "O espectador emancipado", ambos escritos de Jacques Rancière, justamente porque propõem uma emancipação localizada no início do processo de aprendizado e não no final. O que tento apontar em alguns escritos é que essa emancipação poderia ser pensada não somente para as pessoas, mas também para as linguagens - cinema, fotografia, cartografia... - fazendo com que as imagens e linguagens deixassem de ser tomadas como coisas ou estruturas fixas que comunicam ou representam as experiências e passassem a ser tomadas como coisas constituídas pelas e através das experiências, fazendo com que os próprios signos das imagens e linguagens fossem constantemente burilados e desviados de seus sentidos habituais e se reconhecesse, talvez, que uma das maiores potências das linguagens está localizada justamente onde a linguagem falta, ou seja, quando não há signos para expressar alguma experiência a linguagem é forçada a vir a ser outra para poder expressá-la, ampliando assim as possibilidades de dizer da própria linguagem. É, sem dúvida, uma aposta na dimensão estética das imagens - estética como aquilo que atua no sensível -, uma aposta, portanto, na criação como força principal de aprendizados. A força disso para a educação num mundo em forte mudança me parece muito grande, fazendo com que a perspectiva de lidar com as imagens nas escolas a partir da produção me pareça bastante profícua, principalmente se estivermos abertos para lidar com essas imagens-criadas-emescolas como sendo "imagens verdadeiras", no sentido que Fernand Deligny dá a essa expressão: imagens que fazem tropa e voam, que não estão condenadas à linguagem, 
nem submetidas pelos signos intencionais e representacionais, imagens selvagens, que giram e aparecem "para nada”, sem objetivo anterior já definido. Em outras palavras, imagens que sempre atraem outras e outras imagens e forçam o pensamento a pensar, no sentido que Gilles Deleuze aponta para isso, promovendo, talvez, encontros com a diferença que diferencia, com as conexões entre-imagens que extraem sentidos e sem sentidos delas. Ou ainda, em mais outras palavras, imagens que não estejam a serviço somente de comunicar o que já se sabe, mas que também e, principalmente, busquem dar passagem para as experiências que ali ocorrem, afligem e interpelam os corpos humanos e não humanos que configuram cada escola.

Nesse sentido, pensar as imagens a partir da ideia de narrativa me parece reduzir as imagens em suas potencialidades de expressar as experiências. Artistas contemporâneos apontam para isso a algum tempo e, para ficar no exemplo do cinema, filmes como Rua de mão dupla e Acidente, de Cao Guimarães, para exemplificar com o cinema nacional, estão plenos de possibilidades não narrativas para as imagens, mesmo sendo o cinema uma arte fortemente narrativa. Explorar as imagens em educação implica processos de experimentação que não excluam delas nenhuma de suas potências, até porque acredito que algumas dessas potências irão ser descobertas justamente nessas experimentações. Aliás, mesmo a ideia de narrativa tem sido pensada a partir de outras miradas, ao meu ver muito potentes para a relação entre imagens e educação, como a ideia de "narrativas sensoriais" apontada por Osmar Gonçalves, nas quais, citando-o, “atmosferas onde nada de preciso é ainda dado, onde o pensamento apenas se ensaia, se deslocando levemente da experiência". Algo que poderia ser traduzido por imagens que dão passagem para o real que excede a realidade, à experiência conhecida, e que, através, das imagens passa a ser sensível e amplia a realidade. Essas e outras perspectivas apontam para potencialidades das imagens que não são passíveis de ser roteirizadas, previstas, pois acontecem nos acasos, intensidades e imprecisões da própria vida que atravessam as filmagens e as edições. 
PerCursos: A escrita, símbolo da cultura ocidental, foi, ao longo de séculos, e continua sendo, um instrumento de dominação e exclusão, relegando a um não-espaço, a uma pré-história, os povos sem escrita. Não à toa comunidades indígenas Brasil afora têm buscado no vídeo e na fotografia formas de registrar sua própria história, até então compartilhadas pela via da oralidade. Diferente da textualidade, a linguagem (áudio)visual trabalha com a presença do corpo e do gesto, elementos essenciais às formas de contar de muitos povos originários. Nesse sentido, que tipo de contribuições as linguagens sonora, visual e audiovisual podem trazer ao universo das narrativas científicas?

Wenceslao Machado: A escrita faz parte de um processo de dominação, hierarquização e exclusão que é também de disciplinamento do pensamento - como apontam os estudos, por exemplo, em torno da teoria da "forma escolar" - no seio da própria cultura e sociedades ocidentais. Esses estudos apontam a centralidade da escrita no processo de pedagogização da sociedade para muito além da escolarização e também apontam o quanto um certo tipo de escrita atuou e atua no estabelecimento do que é conhecimento e do que é conhecimento escolar. Portanto, não só culturas e sociedades indígenas buscam (e deveriam insistir em continuar a) expressar-se em outras linguagens, como também todas as culturas e grupos sociais que têm na oralidade seu modus operandi de constituição de relações e poderes, pois isso poderá permitir-Ihes escapar das muitas estratégias de dominação presentes na escrita. Estou pensando a oralidade de maneira ampla, como sendo efetivada pelo e no corpo e não somente na voz e nas palavras, conforme aponta Milton Almeida no livro “Imagens e sons - a nova cultura oral”, em que o autor estabelece interessantes relações e sintonias entre oralidade e a produção/recepção de produtos audiovisuais do cinema e da televisão. Uma dessas relações está pautada na perspectiva pasoliniana de que um corpo humano no cinema nos dá sempre um exemplo, mesmo sem dizer uma só palavra. Nesse sentido, todas as culturas orais se beneficiam muito das linguagens audiovisuais por elas serem mais permeáveis a dar passagem a certos conhecimentos que só se efetivam nos gestos, sons e ritmos não passíveis de serem traduzidos em escrita (talvez o seriam traduzidos em escrita poética, aquela escrita que se desafia a si mesma a tornar-se outra para poder expressar algo novo; lembrando que penso tradução sempre a partir de Walter Benjamin). Mas se esses "registros exemplares" feitos em linguagens em imagens e sons irão se legitimar como conhecimento científico (no sentido de objetivo, verificável, 
generalizável e universal) é algo pouco provável, pois me parece que esses conhecimentos colocam as próprias noções de objetividade, universalidade, generalização e verificação científicas sob questionamento, justamente por serem fortemente vinculados a um modo de vida específico e mesmo a um corpo e ambiente específicos. Em outras palavras, são conhecimentos fortemente vinculados à experiência e, como tais, não são generalizáveis, reproduzíveis ou representáveis. Mas essa é só uma perspectiva de ciência e ela pode (e já tem sido) ser entendida de outras maneiras, sob outras perspectivas. Por exemplo, se pensarmos a ciência na perspectiva que Walter Benjamin traça em "O narrador" com a noção de conselho - algo não a ser seguido e imitado, mas alterado em cada contexto, incorporado - talvez esses conhecimentos e essas sociedades e culturas venham a ter o mesmo respeito e credibilidade que a ciência hegemônica possui atualmente. Na verdade, esse respeito e credibilidade já ocorre em certos grupos sociais e acadêmicos que, normalmente, já estabeleceram fortes críticas a esse conhecimento científico, apontando-o como restrito e restritivo, como os escritos de Eduardo Viveiros de Castro deixam transparecer de maneira incisiva e acolhedora.

Enfim, eu deveria iniciar a resposta com outra pergunta, "o que seriam atualmente narrativas científicas?" Registrar sua história ou contar histórias seriam narrativas científicas? O parâmetro para ser científico seria dado pela própria pessoa ou cultura que registra e conta ou seria dado pela cultura que inventou a ciência e dela tem o domínio para dizer o que está ou não dentro dela? Se pensarmos nas imagens e sons, que não só contam ou registram, quais seriam os dispositivos - métodos? - para se criar uma obra científica? Seriam os mesmos dispositivos utilizados nos documentários habituais do tipo Globo Repórter? Imagino que não, pois os próprios documentaristas já deixaram claro que o cinema documenta principalmente as maneiras do cinema documentar e cineastas como Eduardo Coutinho já disseram frases geniais como "Não estou preocupado com a filmagem da verdade, mas com a verdade da filmagem". Então porque insistir em narrativas científicas audiovisuais a não ser para redefinir a própria ideia e poderes do que seja ciência, verdade, realidade? Essa me parece ser a principal contribuição das linguagens audiovisuais à ciência: o seu próprio questionamento e disposição para tornarse permeável àquilo que ainda não é ciência, mas é conhecimento e experiência. E eu diria 
que muitos documentaristas contemporâneos já têm feito isso através de sua enorme abertura para o não roteirizado, para o encontro com o "outro inusitado", para ensaiar formas de filmar que investem o próprio cinema de outras miradas que tensionam a própria sensação de documento da imagem, apontando, sobretudo, a impossibilidade de filmar a verdade ou a realidade como a mais estimulante descoberta para que eles inventem outras maneiras de filmar e editar aquilo que o próprio cinema cria como realidade, outras relações e mundos que vieram a existir justo porque o cinema aportou ali.

PerCursos: Falando em narrativa científica, propostas têm sido elaboradas - até mesmo no âmbito das hard sciences - para tornar mais visuais as publicações acadêmicas, em luta por um mercado de leitores altamente identificados à linguagem das imagens. Projetos da iniciativa privada, como o Mind the Graph (www.mindthegraph.com), dão mostras de tal necessidade que parte, sobretudo, da perspectiva do consumo de informação. Como você enxerga tais ações e que previsões/sugestões podem ser feitas no campo das humanidades?.

Wenceslao Machado: Essa pergunta me interessa especialmente porque sinto que ela diz respeito a duas coisas muito caras a mim e que estão sob questão atualmente: a educação e a democracia. Nos dias que correm, em que fortes mudanças ocorrem nos poderes e possibilidades sociais (e sentimos o esgotamento de certas certezas quanto à democracia representativa e à educação cumulativa), nos perguntamos quase todo o tempo, “que tipo de democracia gostaríamos (e seria possível)?”, “que tipo de educação gostaríamos (e seria possível)?" Isso faz com que essa busca de tornar mais visuais as publicações acadêmicas estabeleça uma relação mais ampla que com um mercado já dado de leitores (os acadêmicos), pois ela se auto justifica também pela busca de maior inclusão de leitores não acadêmicos - algo atinente à democracia - e se realiza num amálgama complexo com a divulgação científica da qual, me parece, emanam muitas das descobertas que os artigos acadêmicos têm se beneficiado. Nesse sentido, experiências e estudos bem interessantes, sobretudo porque tensionam a própria ideia de ciência e divulgação científica, têm sido realizados no Laboratório de Estudos Avançados em Jornalismo-LABJOR da Unicamp, onde a mescla entre arte, ciência, política e cultura é a tônica de muitas produções, as quais situam-se, muitas vezes, num entre arte e ciência. 
Nesses e em outros estudos e produções da divulgação científica, a dimensão educativa está bastante presente, tendo em vista que divulgar ciência é também formar uma ou múltiplas ideias acerca do que vem a ser ciência e de suas (im)possibilidades para lidar com nossos problemas atuais. Problemas como aquilo que nos força a pensar, não como algo que deva ser solucionado. Agora notei o quanto acadêmico estou sendo nessa entrevista, pois já expliquei várias palavras para que seus sentidos sejam entendidos como gostaria que fossem (risos). Imagino que se fosse uma entrevista oral isso não ocorreria ou ocorreria bem menos...

Bom, retornando à pergunta, talvez seja essa imanente dimensão educativa da divulgação científica - e penso que nós acadêmicos temos nos tornado divulgadores de ciência enquanto divulgadores de nós próprios -, que faz com que as imagens venham a figurar como parte cada vez mais importante dela. Afinal, não há propriamente nada de novo em educar através da visualidade que as imagens trazem para um texto, independente se educar seja pensado nas mais variadas acepções: ensinar, aprender, informar, seduzir, conformar, memorizar, disciplinar, pensar... As imagens estão presentes na educação ocidental faz muito tempo. Por exemplo, no século XVII, Jean Amós Comenius foi autor da "Didática Magna", um dos livros considerados inauguradores da forma moderna de pensar a educação, e de "Orbis Pictus", considerado o primeiro livro didático ilustrado e a primeira cartilha do mundo ocidental, colocando as imagens no centro do processo educativo.

Em outras palavras, penso que essa investida acadêmica nas imagens é produto de muitas coisas, incluindo aí as disponibilidades técnicas advindas do meio digital, e que por isso qualquer previsão de futuro implicaria considerar muito mais coisas do que dou conta. Arrisco sugerir que seria muito interessante, principalmente nas Humanidades, investir cada vez mais em diferentes formas de escrita-divulgação-aprendizado científico através das imagens, sobretudo, porque isso implicaria na maior possibilidade de inclusão de outros tipos de saberes, conhecimentos e experiências no rol do que é ou pode vir a ser considerado ciência (ou algum outro tipo de conhecimento legítimo e legitimado pela academia) e no rol de imagens que poderiam compor as publicações científicas (para além das utilizadas para facilitar, comprovar ou ilustrar o que está escrito). Mas isso 
implicaria, talvez, que também tenhamos que nos tornar cada vez mais divulgadores de nós mesmos enquanto divulgadores de nossas produções e descobertas científicas e isso pode implicar, como penso já tem implicado, na redução das próprias descobertas e invenções, pois seremos cada vez mais afetados pelo "gosto" dos (e)leitores. Muitas perguntas se colocam: como arriscar na invenção de outros tipos de narrativas científicas - como as audiovisuais, aproximadas ou não da arte - se temos que capturar leitores e citadores para as estatísticas acadêmicas que regulam cada vez mais nossas possibilidades de financiamento e divulgação? Como democratizar a ciência produzida por nós sem incluir outros grupos sociais que só nos lerão se inventarmos outras maneiras de nos comunicar/expressar/divulgar (e aí perdemos os antigos leitores e citadores...)? Como fazer com que as imagens sejam estratégicas de permeabilização entre as pessoas e grupos sociais que estudamos e as produções que realizamos? Antropólogos, etnógrafos e "cartógrafos sociais", bem como cineastas, fotógrafos e outros artistas, já vêm experimentando isso faz muitos anos e podem nos dar boas pistas das (im)possibilidades para as (não)narrativas científicas quando atravessadas pelas imagens não só na sua publicação/divulgação de "resultados", mas também na própria produção - a pesquisa - desses "resultados", sejam eles experiências ou experimentos, afinal um dos "resultados" são os próprios textos-imagens desdobrados na e da pesquisa. Mas arrisco dizer, por fim, que me parece séria a mistura desses saberes acumulados, as trocas entre cientistas e artistas das imagens, que poderia ser a melhor aposta para as Humanidades, inclusive para romper com a nossa "necessidade de ciência" ou para acolher outras possibilidades de pensar a ciência a partir das imagens, como a "ciência inquieta" de Aby Warburg, retomada e discutida recentemente no livro “Atlas ou a Gaia Ciência Inquieta”, de Georges Didi-Huberman, em que as imagens aparecem como "minas" na dispersão do mundo e o pensamento-imaginação se dá também e principalmente nos espaços escuros entre as imagens das grandes pranchas que Warburg criou.

PerCursos: 0 documentarista João Moreira Salles, em entrevista (https://www.youtube.com/watch?v=J6cjVR_tTxc), fala sobre o paradoxo da informação $x$ experiência na linguagem do documentário. Em oposição ao jornalismo informativo 
tradicional, propõe a poética cinematográfica que busca proporcionar uma experiência transformadora ao espectador. A imagem e o som são, nesta perspectiva, agentes: criam o real e encantam/ritualizam a vida, sem a pretensão de narrá-los. O senhor acredita que, no campo da ciência, tal mudança de foco, que representaria um novo "giro narrativo", seria possível?

Wenceslao Machado: Esse trecho da entrevista é delicioso de ouvir, ainda mais na voz e no “encantamento ético e engajado" desse cineasta. Sou fã dele e isso dificulta um pouco me desfazer desse lugar de encanto onde ele me coloca - ao me lembrar de seus filmes para escrever algo para além do que ele já disse. Minha vontade é dizer que ele já disse tudo e que talvez fosse muito bom se as Humanidades tomassem essa ética cinematográfica como mote em suas pesquisas e aproximações do mundo. Mas vou tentar seguir por um outro caminho, através de minhas próprias pesquisas para dar alguma resposta mais pessoal.

Gosto de pensar que isso, essa revalorização da experiência no lugar da informação, já vem ocorrendo em algumas áreas das Humanidades onde as perguntas feitas para o mundo tem sido outras. Ao invés de “o que é isso?" pergunta-se "o que pode isso?" ou “o que pode vir a ser isso?", fazendo com que haja um deslocamento da tentativa do cientista de dizer o que seria aquele conjunto de experiências e relações humanas (representando-as e, de certa forma, paralisando-as), para a tentativa de recolher "o que experiências singulares poderiam trazer de aprendizado às outras pessoas" (destacando essas singularidades do fluxo comum e deixando que suas potências sejam ou não incorporadas pelos demais). As duas perspectivas não se opõem, mas certamente se tensionam em suas buscas por legitimidade e força políticas, em grande medida por elas lidarem com "filosofias" bastante distintas, as quais simplifico (correndo todos os riscos disso) em filosofias da identidade (do ser) e da diferença (do devir). Talvez fosse o caso de dizer das estruturas e das pós-estruturas. Ou das informações e das conexões. Ou... Certamente essas dicotomias estão aqui apenas para tentar pensar o "problema da experiência", pois não as penso como oponentes, muito pelo contrário, sinto-as como produto e produtoras de variações diversas em nossas práticas de pesquisa e escrita científicas. Mas, mais uma vez, o problema talvez esteja na ciência... 
Em outras palavras, penso que esse giro na relação com a experiência seria sim possível e desejável. Minha dúvida é se pensar esse giro em direção à experiência como conhecimento "científico" legítimo implica inevitavelmente em ele ser narrativo. Acho que essa é uma disposição, e um desejo, dos historiadores, não? Para mim, que estou na Educação, venho da Geografia e tenho estudado o cinema contemporâneo, a narrativa pode ser parte do "problema" para reintroduzir a experiência como conhecimento. Especialmente gosto da perspectiva de pensar a experiência como não sendo algo interior, mas sim um composto de externalidades que afetam um corpo. Aqui há uma forte marca de minhas leituras da geógrafa Doreen Massey e da "Ética” de Espinosa, mas também da concepção de língua e linguagem como expressões sempre em devir de corpos afetados pelo mundo. Nesse sentido, para narrar, precisamos mais do que escolher uma língua ou linguagem pronta, precisamos inventar essa língua ou linguagem para que ela possa expressar as experiências que nos atravessam. É verdade que isso se torna mais exigente e necessário quando as experiências que estão sendo ou a serem narradas são tão novas e imprevistas que só encontramos silêncio nas línguas e linguagens existentes. Aqui estou falando a partir dos escritos sobre testemunho de Eugénia Vilela, filósofa que finaliza seu livro "Silêncios tangíveis - corpo, resistência e testemunho nos espaços contemporâneos de abandono" indicando as potencialidades da fotografia para dar passagem expressiva aos silêncios daqueles que não conseguem testemunhar suas experiências. É nesse sentido que uma fotografia do livro "Êxodos", de Sebastião Salgado, expressa - testemunha - experiências não sendo uma narrativa, ainda que narrativas possam atravessar essa fotografia de muitas e muitas maneiras.

Recentemente, tenho me encantado bastante com a perspectiva colocada nas "imagens para nada", de Fernand Deligny, que propõe maior potência para as imagens justamente quando elas não se propõem a dizer nada em específico, sendo, portanto, livres, selvagens. No entanto, ainda estou ensaiando algumas aproximações com essa perspectiva, principalmente associando-a à importância que Deligny estabelece para o lugar - o terreno - onde se vive, em detrimento da linguagem na constituição do humano. 
Para além disso, e retornando ao cinema, experimentações diversas, como as já referidas "narrativas sensoriais" ou as de "desroteiros", apontam para as potencialidades de conhecer não propriamente as experiências já existentes, mas de criar outras experiências com e através do processo de aproximação do mundo. Penso que algo semelhante tem sido experimentado em algumas pesquisas das Humanidades a partir do (não) método cartográfico, desdobrado do conceito de rizoma de Deleuze e Guattari. Os escritos que vêm a existir a partir dessas pesquisas, via de regra, são fragmentários e muitas vezes atravessados por imagens, mesmo porque, a exemplo do que já vinha ocorrendo com as pesquisas realizadas sob a perspectiva do cotidiano, a escrita não é outra coisa senão a (ou parte da) própria pesquisa, os autores grafando muitas vezes a expressão escrita-pesquisa. Os “cartógrafos rizomáticos” produzem muitas imagens mapas - e poderiam muito bem escrever algo como imagem-pesquisa, a qual também não necessariamente será narrativa e expressará a experiência de pesquisa na própria imagem, como imagem.

Por fim, para não perder a oportunidade de lembrar estudos que foram muito importantes em minha formação de pesquisador das imagens e da educação e cultura visuais, cito aqui a noção de "imagens agentes", proveniente do texto "Ad Hereniumm" e muito presente nos artigos e livros do já citado Milton José de Almeida em seus estudos sobre as relações entre as imagens e a Arte da Memória, em especial no livro "Cinema arte da memória”, em que o “Ad Hereniumm” está publicado em português como um dos memorandos do livro. Deixo aos leitores a curiosidade para descobrirem as belezas dessa perspectiva do agenciamento das imagens na criação do real e da realidade que, no livro citado, é apresentada e exemplificada com afrescos de igrejas e palácios públicos antes de chegarem a configurar as telas de cinema.

PerCursos: Em meio às possibilidades e limites inerentes ao uso de linguagens não-textuais no ensino e nas narrativas acadêmicas, reside uma questão que tem sido, há algum tempo, o cerne das resistências às tentativas de expandir a escrita científica para além do texto: a ciência e, sobretudo, os cientistas (sociais) comportariam trabalhar com narrativas abertas e questionadoras, suavizando o ideal de objetividade que lhe é característico em prol de novas formas de diálogo e compartilhamento de saberes com a sociedade? O que o senhor pensa sobre isso? 
Wenceslao Machado: Penso que sua pergunta já contém minha resposta: é uma questão de poder ao mesmo tempo em que é uma questão de saber. Me lembrei de uma frase que gosto muito e que abre o livro "História da arte", do Gombrich, "Nada existe realmente a que se possa dar o nome arte. Existem somente artistas”. Ela não seria válida também para as relações entre ciência e cientistas? Penso que sim. Como tal, nós acadêmicos comportaríamos - como alguns de nós já comportamos - trabalhar mais com imagens e formas questionadoras e abertas na medida mesma em que formos conseguindo encontrar espaços, legitimidades e poderes onde essas novas escritas atravessadas ou não por imagens - forem sendo estabelecidas e também na mesma medida em que o lugar do detentor do "saber sobre" (tido como exterior e objetivo e, por isso, neutro) se fizer tão importante quanto o do "saber com" (incorporado e contextualizado, não propriamente subjetivo, mas compartilhado, experienciado). Em outras palavras, penso que os cientistas sociais que estão se abrindo e que vierem a se abrir a essas outras possibilidades de produção e divulgação de conhecimento estão e estarão se abrindo também para outras experiências de saber-poder, não necessariamente deslocados do Estado, das universidades ou de outros poderes estabelecidos, mas certamente sem a disposição habitual desses lugares de poder, aquela disposição para dizer aos outros o que para eles é a vida deles e também o que seria melhor para melhorá-la, ou aquela outra disposição para utilizar a vida dos outros somente como campo de pesquisa para escrever sobre ele e angariar poder e relações entre outros campos e vidas, mais acadêmicas, por exemplo.

Enfim, como está em sua pergunta, é uma questão de lidar com o saber e o conhecimento como algo produzido e distribuído de maneira compartilhada. Talvez por isso a palavra genérica "sociedade" me incomode um pouco, pois ela apaga essas diferenças de poderes que afeta diretamente o compartilhamento efetivo dos saberes. Em outras palavras, me parece que seria preciso deixar mais explicitado que certos saberes e modos de produção e divulgação empoderam certos grupos sociais e que produzir um “saber genérico e generalizável” é empoderar os grupos que têm acesso facilitado a ele, ou seja, os já estabelecidos no poder. Penso que muitos cientistas e grupos de pesquisa já fazem isso: o exemplo do Eduardo Viveiros de Castro me parece 
muito bom, mas poderíamos pensar em Paulo Freire também e no grupo em torno da Cartografia Social, que começou na Amazônia brasileira e se espalhou pelo país afora, e em projetos do tipo "Olhares Cotidianos (re)velam o Programa Turismo CO2 neutro", realizado numa parceria entre universidades, ONGs e comunidades rurais do sul da Bahia onde nas fotografias, tiradas por todos os grupos participantes, buscou-se muito mais do que as informações sobre um programa de redução de $\mathrm{CO}_{2}$, pois nelas buscou-se dar passagens ao mundo sensível vivido pelos pequenos agricultores (nas publicações resultantes desse projeto, pode-se notar como as imagens - e os textos - fluem em formatos e sentidos diversos: abertos, surpreendentes, amorosos, esquisitos e informativos a um só tempo). Ainda que sejam a minoria, há muitos outros projetos artísticos, científicos e mistos como esse, que se dedicaram e se dedicam a inventar maneiras de produzir, junto com comunidades diversas, imagens e palavras que criem passagens para as experiências vividas nessas comunidades, bem como as pessoas envolvidas nessas pesquisas e experimentações inventem outras experiências justamente na participação nesses projetos. Em poucas palavras: inventem poderes na medida mesma em que inventam mundos sensíveis onde venham habitar suas experiências.

Recebida em: 08/05/2016 Aprovada em: 09/05/2016

Universidade do Estado de Santa Catarina - UDESC Centro de Ciências Humanas e da Educação - FAED

Revista PerCursos Volume 17 - Número 33 - Ano 2016 revistapercursos@gmail.com 